JANAINA DA COSTA PEREIRA TORRES DE OLIVEIRA

EVOLUÇÃO DA MICROESTRUTURA E DA TEXTURA DURANTE A LAMINAÇÃO A FRIO E A RECRISTALIZAÇÃO DE ALUMÍNIO COM DIFERENTES NÍVEIS DE PUREZA. 
JANAINA DA COSTA PEREIRA TORRES DE OLIVEIRA

\section{EVOLUÇÃO DA MICROESTRUTURA E DA TEXTURA DURANTE A LAMINAÇÃO A FRIO E A RECRISTALIZAÇÃO DE ALUMÍNIO COM DIFERENTES NÍVEIS DE PUREZA.}

Tese apresentada a Escola Politécnica da Universidade de São Paulo para obtenção do título de Doutor em Engenharia.

São Paulo 


\title{
EVOLUÇÃO DA MICROESTRUTURA E DA TEXTURA DURANTE A LAMINAÇÃO A FRIO E A RECRISTALIZAÇÃO DE ALUMÍNIO COM DIFERENTES NÍVEIS DE PUREZA.
}

\author{
Tese apresentada a Escola Politécnica da \\ Universidade de São Paulo para obtenção do \\ título de Doutor em Engenharia. \\ Área de Concentração: \\ Engenharia Metalúrgica e de Materiais \\ Orientador: \\ Prof. Dr. Angelo Fernando Padilha
}

São Paulo 
Este exemplar foi revisado e alterado em relação à versão original, sob responsabilidade única do autor e com a anuência de seu orientador.

São Paulo, de Maio de 2009.

Assinatura do autor

Assinatura do orientador

FICHA CATALOGRÁFICA

Oliveira, Janaina da Costa Pereira Torres de

Evolução da microestrutura e da textura durante a laminação a frio e a recristalização de alumínio com diferentes níveis de pureza / J.C.P.T. de Oliveira. - ed.rev. -- São Paulo, 2009.

$261 \mathrm{p}$.

Tese (Doutorado) - Escola Politécnica da Universidade de São Paulo. Departamento de Engenharia Metalúrgica e de Materiais.

1.Alumínio 2.Laminação 3.Difração por raios $X$ 4.EBSD I.Universidade de São Paulo. Escola Politécnica. Departamento de Engenharia Metalúrgica e de Materiais II.t. 
Dedico este trabalho ao meu filho Matheus Torres Pereira que suportou a minha ausência e soube esperar a minha volta para casa sempre alegre,

ao meu esposo Valmir Torres de Oliveira pelo incentivo, pelo auxílio e por mostrar que obstáculos existem para serem superados,

aos meus pais Ozeni Elias Pereira e Nadir da Costa Pereira que dedicaram grande parte da sua vida forjando o meu caráter e auxiliando-me em todos os momentos e a minha amiga Marly Silveira Araújo por mostrar que a junção de pequenas ações permite grandes realizações. 


\section{AGRADECIMENTOS}

Primeiramente a Deus por permitir que eu realizasse este trabalho.

Ao Prof. Dr. Angelo Fernando Padilha pela compreensão, paciência, respeito, tempo dedicado e pelo grande incentivo na minha vida acadêmica demonstrados na orientação deste trabalho.

Ao Departamento de Engenharia Metalúrgica e de Materiais da Escola Politécnica da Universidade de São Paulo (PMT-EPUSP) pela oportunidade da realização desse estudo.

Ao Conselho Nacional de Desenvolvimento Científico e Tecnológico, CNPq, pela bolsa de doutorado (Processo n ${ }^{\circ}$ 141981/2005-9) concedida.

Ao Prof. Dr. Paulo Rangel Rios (UFF-Universidade Federal Fluminense) pelo incentivo e confiança.

Ao Prof. Dr. Nelson Batista de Lima (IPEN/CNEN-SP) por disponibilizar o laboratório de difração de raios $\mathrm{X}$ e pelas valiosas sugestões e discussões no decorrer do trabalho.

Ao Dr. Eng. Ricardo do Carmo Fernandes (CBA-Companhia Brasileira do Alumínio) pelo fornecimento das amostras dos alumínios de pureza comercial.

Ao Diretor Industrial Eider Alberto Simielli (ALCOA AMERICANA) pelo fornecimento das amostras do alumínio super puro.

Aos funcionários da secretaria do Departamento de Engenharia Metalúrgica e de Materiais (PMT) e da seção de pós-graduação (SPG) da Escola Politécnica da Universidade de São Paulo (EPUSP).

Ao técnico Renê Ramos de Oliveira (IPEN/CNEN-SP) pela colaboração nas análises de difração de raios $X$.

À Dra. Clarisse Terui Kunioshi (PMT-EPUSP) pelo excelente trabalho de microscopia eletrônica de varredura. 
Ao técnico Vinícius Freire Elias (PMT-EPUSP) pelas análises de EBSD.

Ao técnico Nildemar Aparecido Messias Ferreira (IPEN/CNEN-SP) pela colaboração nas análises no microscópio eletrônico de transmissão.

À Dra. Marina Magnani (PMT-EPUSP) pela preparação das amostras para análise no microscópio eletrônico de transmissão.

Aos técnicos Ivan Menegueço, Miguel Borodiak e Alex Sandrto Felipe de Moraes (CBACompanhia Brasileira de Alumínio) pela ajuda nas análises metalográficas por microscopia de luz polarizada.

Ao técnico Luís Carlos da Silva (IPEN/CNEN-SP) pelo auxílio no uso do equipamento de polimento eletrolítico.

À técnica Sandra Munarin (IPT - Instituto de Pesquisas Tecnológicas) pelo auxílio nas laminações realizadas nesse trabalho.

Ao técnico Cláudio Roberto dos Santos (PMT-EPUSP) pelo auxílio no uso dos equipamentos do laboratório de metalografia.

Aos técnicos Jovanio de Oliveira Santos e Leandro Justino de Paula (PME-EPUSP) pelo auxílio no aprendizado do polimento mecânico e pelas informações cedidas para os mesmos.

Aos técnicos José Rubens Bezerra de Carvalho e Antônio Lívio da Silva Nunes (PMT-EPUSP) pela paciência e disposição sempre presente.

Aos bibliotecários Gilberto Martins e Clélia de Loudes Lara Meguerditchian (PMT-EPUSP) pela incansável ajuda e disposição na procura e correções das referências bibliográficas.

À Cláudia Regina Serantoni e Tarita Furlan (IPT - Instituto de Pesquisas Tecnológicas) pelas inúmeras vezes que me incentivaram a continuar esse trabalho.

À Clara Herrera (PMT-EPUSP) pela disposição e tempo investido na minha adaptação a USP. 
Aos colegas da pós-graduação (PMT-EPUSP) Adolfo, Alberto, Alexandre, Angelo, Dairo, Dener, Denilson, Diana, Doris, Douglas, Eduardo, Evaldo, Fausto, Flávio, Juan Marcelo, Maysa, Márcio, Maria do Carmo, Mário, Olmede, Paula Fernanda, Paulo, Roberta, Vivian e Wanderson que direta ou indiretamente na troca de informações e discussões contribuíram com o enriquecimento deste trabalho. 
A Lei do Senhor é perfeita; ela devolve à nossa alma as forças perdidas. A revelação da vontade de Deus é digna de confiança; ela dá sabedoria a quem estiver disposto à aprender.

(S1. 19:7) 


\section{RESUMO}

O presente trabalho teve como objetivo principal estudar a evolução da microestrutura e da textura cristalográfica de três alumínios de pureza comercial com diferentes níveis de pureza, AA1 100 (99,00\%), AA1050 (99,50\%) e AA1070 (99,70\%), e do alumínio super puro, AA1199 (99,995\%). A obtenção das placas de alumínio de pureza comercial foi feita pelo processo Direct Chill (DC) seguido de homogeneização e laminação a quente até a espessura final de $10 \mathrm{~mm}$ e o alumínio super puro foi produzido em laboratório e encontrava-se na forma de blocos fundidos.

Foram utilizadas várias técnicas de análise microestrutural: microscopia óptica convencional, microscopia óptica com luz polarizada, microscopia eletrônica de varredura, microscopia eletrônica de transmissão, medidas de condutividade elétrica e dureza Vickers. Já a evolução da textura do material foi analisada pela técnica de difração de raios $\mathrm{X}$, nos alumínios de pureza comercial e pela técnica de difração de elétrons retroespalhados (EBSD), no alumínio super puro.

No estado "como recebido" e recozido a $400{ }^{\circ} \mathrm{C}$ por 1 e 24 horas foi possível observar que nos alumínios de pureza comercial produzidos pelo processo DC não há variações na composição química ao longo da espessura. Os precipitados nos alumínios AA1100 e AA1070, no estado "como recebido" estavam distribuídos na direção de laminação, porém com vários locais de aglomeração dos mesmos, e no alumínio AA1050 os mesmos estavam finamente dispersos na direção de laminação. Após recozimento a $400{ }^{\circ} \mathrm{C}$ por 1 e 24 horas as mesmas características foram mantidas, porém ocorreu um aumento na fração volumétrica do estado "como recebido" para os recozidos a $400{ }^{\circ} \mathrm{C}$, ou seja, ocorreu precipitação durante o recozimento. Quanto a análise da textura dos alumínios de pureza comercial, na superfície encontrou-se a textura de cisalhamento, devido ao esforço mecânico entre o cilindro de laminação e as amostras, tanto no estado "como recebido" como após os recozimentos. A 1/4 da espessura e no centro do material após recozimentos ainda observou-se a textura de cisalhamento, mas também as texturas tipo cubo, cubo rodado e latão. No centro do material permaneceram a textura tipo cubo e latão. Já o alumínio AA1199 possui uma estrutura grosseira (grãos oligocristalinos), sem a ocorrência de precipitados e não foi possível obter resultados nas análises de textura, devido ao tamanho de grão grande.

Após a laminação a frio com aproximadamente $70 \%$ de redução em espessura, seguido de tratamentos isócronos no tempo de 1 hora e nas temperaturas de 50,100, 150, 200, 250, 
300, 350, 400 e $500{ }^{\circ} \mathrm{C}$, o alumínio AA1199 apresentou uma menor temperatura para completa recristalização, em torno de $280{ }^{\circ} \mathrm{C}$, seguido do alumínio AA1050 (375 $\left.{ }^{\circ} \mathrm{C}\right)$ e dos alumínios AA1100 e AA1070 (ambos, $400{ }^{\circ} \mathrm{C}$ ). Como as composições químicas das soluções sólidas matrizes são praticamente idênticas, a variação na temperatura de recristalização deve ser atribuída aos precipitados presentes no alumínio que quando finamente dispersos na matriz impedem o movimento dos subcontornos, retardando o início da recristalização. $\mathrm{O}$ alumínio AA1199 possui uma temperatura para completa recristalização, menor, em relação aos outros alumínios, uma vez que não possui precipitados em sua microestrutura. Quanto a textura, na superfície e a 1/4 da espessura, os alumínios de pureza comercial laminados a frio sem tratamento térmico, permaneceram com a textura de cisalhamento encontrada na superfície no estado "como recebido" com o surgimento da textura S. Após o tratamento térmico a $250{ }^{\circ} \mathrm{C}$ por 1 hora apareceu a textura Goss e a $350{ }^{\circ} \mathrm{C}$ por 1 hora a textura tipo cubo, cubo rodado e cubo ND, lembrando que em ambos os casos a textura de cisalhamento e $\mathrm{S}$ permaneceram. Com o auxílio da utilização da técnica de difração de elétrons retroespalhados (EBSD) encontrou-se no alumínio AA1199, a textura tipo cubo, tanto laminado a frio sem tratamento térmico quanto após os tratamentos.

Após a laminação a frio com aproximadamente $80 \%$ de redução em espessura, seguida de tratamentos isotérmicos, nas temperaturas de 150,250 e $350{ }^{\circ} \mathrm{C}$ e nos tempos de $1 / 2,1,2,3$ e 4 horas, os alumínios de pureza comercial apresentaram uma temperatura para completa recristalização em torno de $350{ }^{\circ} \mathrm{C}$ e por meio da técnica de microscopia eletrônica de transmissão observou-se arranjos celulares de discordâncias, mas não foram detectadas diferenças significativas entre esses arranjos apresentados pelos três alumínios. Diferenças certamente existem, mas para serem caracterizadas é necessário um estudo detalhado com microscopia eletrônica de transmissão. A presença de partículas de compostos intermetálicos foi observada em todas as amostras analisadas, essas partículas são resultado da baixa solubilidade do ferro e do silício no alumínio e se formaram durante as diversas etapas do processamento dos materiais. 


\begin{abstract}
The present work had as main objective to study the evolution of the microstructure and crystallographic texture of three commercial purity aluminums with different levels of purity, AA1100 (99.00\%), AA1050 (99.50\%) and AA1070 (99.70\%), and of the super pure aluminum, AA1199 (99.995\%). The plates of commercial purity aluminum were obtained through direct chill (DC) process followed by homogenization and hot rolling until the final thickness of $10 \mathrm{~mm}$. The super pure aluminum was produced in laboratory and was in the "ascast" condition.

Several techniques of microstructural analysis were used: conventional optical microscopy, optical microscopy using polarized light, scanning electron microscopy, transmission electron microscopy, measurements of electrical conductivity and Vickers hardness. The evolution of the texture of the commercial purity aluminum was analyzed by Xray diffraction and the super pure aluminum was analyzed using electron backscatter diffraction.

Variations in the chemical composition along thickness in the commercial purity aluminum produced by the DC process in the "as-received" condition and after annealing at $400{ }^{\circ} \mathrm{C}$ for 1 and 24 hours were possible to observe. The precipitates in the aluminum AA1100 and AA1070, in the "as-received" condition were distributed in the rolling direction, including several sites of clusters of the same precipitates. In the aluminum AA1050 the precipitates were finely dispersed in the rolling direction. After annealing at $400{ }^{\circ} \mathrm{C}$ for 1 and 24 hours the precipitate characteristics were maintained, and there was an increase in the volumetric fraction of the "as-received" condition in comparison to samples annealed at 400 ${ }^{\circ} \mathrm{C}$, showing that precipitation occurred during annealing. The shear texture was observed in the commercial purity aluminums, either in the "as-received" condition or after annealing, and this effect was due to the mechanical effort between the rolling mill and the samples. At $1 / 4$ of the thickness and in the center of the material after annealing the shear texture was still observed, and also the type cube, rotated cube and brass textures. The center of the material continues showing the type cube and brass textures. On the other hand, the aluminum AA1199 has a coarse structure (oligocrystalline grains), without the occurrence of precipitates, and texture results were not obtained due to the fact the grains are much coarser, due to the size of big grain.
\end{abstract}

After cold rolling with approximately $70 \%$ of reduction in thickness, followed by 
isochronous treatments for 1 hour at temperatures of 50,100,150,200,250,300,350, 400 and $500{ }^{\circ} \mathrm{C}$, the aluminum AA1199 presented a smaller temperature for complete recrystallization, around $280{ }^{\circ} \mathrm{C}$, followed by the aluminum AA1050 $\left(375^{\circ} \mathrm{C}\right)$ and of the aluminum AA1100 and AA1070 (both, $400{ }^{\circ} \mathrm{C}$ ). As the chemical compositions of the solid solutions matrixes are almost identical, the variation in the recrystallization temperature should be attributed to the presence of precipitates in the aluminum, and when finely dispersed in the matrix they impede the movement of the sub-boundary, delaying the beginning of the recrystallization. In comparison to the other aluminums, the aluminum AA1199 has a smaller temperature for complete recrystallization, since there are not precipitates in its microstructure. Observing the texture, in the surface and the $1 / 4$ of the thickness, the commercial purity aluminums, after cold rolling and without heat treatment, showed the shear texture found in the surface in the "as-received" condition with the appearance of the $\mathrm{S}$ texture. After heat treatment at $250{ }^{\circ} \mathrm{C}$ for 1 hour the Goss texture appeared and at $350{ }^{\circ} \mathrm{C}$ for 1 hour the type cube, rotated cube and cube ND textures; notice that in both cases the shear and $\mathrm{S}$ texture were still present. Energy dispersive $\mathrm{X}$-ray spectroscopy (microanalysis) showed in the aluminum AA1199, the texture type cube, so cold rolled without heat treatment as after the treatments.

After cold rolling with approximately $80 \%$ of reduction in thickness, followed by isothermal treatments, at temperatures of 150,250 and $350^{\circ} \mathrm{C}$ and times of $1 / 2,1,2,3$ and 4 hours, the commercial purity aluminum presented a temperature for complete recrystallization around $350{ }^{\circ} \mathrm{C}$. Transmission electron microscopy technique showed dislocations cellular arrangements, but significant differences were not detected among those arrangements presented by the three aluminums. Differences certainly exist, but for their characterization detailed study with transmission electron microscopy is necessary. The presence of particles of intermetallic compounds were observed in all analyzed samples, those particles resulted of the low solubility of iron and silicon in the aluminum and were formed during the several stages of the processing of the materials. 


\section{LISTA DE ILUSTRAÇÕES}

Figura 2.1 - Limite de resistência, limite de escoamento e dureza em função do teor de pureza.

Figura 2.2 - Diagrama de fases do sistema Al-Fe........................................................... 48

Figura 2.3 - Projeção solvus do sistema Al-Fe-Si............................................................ 49

Figura 2.4 - Escala de comprimento da solidificação......................................................... 52

Figura 2.5 - Corte longitudinal de um lingote apresentando esquematicamente as três zonas estruturais

Figura 2.6 - Efeito do tratamento térmico de homogeneização na micro-segregação do lingote...

Figura 2.7 - Desenho esquemático de tipos de laminadores utilizados na laminação.

Figura 2.8 - Desenho esquemático da laminação a quente.

Figura 2.9 - Mecanismos de restauração (recuperação e recristalização) possíveis durante a laminação a quente (baixa deformação) do alumínio.

Figura 2.10 - Efeito dos átomos de impureza, no alumínio super puro, na recristalização estática após a laminação a quente (temperatura de entrada e saída da laminação a quente foi respectivamente 500 e $390{ }^{\circ} \mathrm{C}$ )

Figura 2.11 - Desenho esquemático da laminação a frio.

Figura 2.12 - Curva esquemática tensão-deformação para um monocristal CFC.

Figura 2.13 - Desenho esquemático de microestruturas no estado encruado em amostras após: (a) deformações intermediárias $(\varepsilon=0,06-0,08)$ e (b) grandes deformações $(\varepsilon>1) \ldots . .67$

Figura 2.14 - Arranjo celular, esquemático, de discordâncias em grão encruado.

Figura 2.15 - Desenho esquemático dos vários estágios da recuperação de um material deformado plasticamente

Figura 2.16 - A recuperação do alumínio de 99,999\% de pureza com um grau de deformação de cisalhamento (torção) de 6,91 a $-196{ }^{\circ} \mathrm{C}$, medido por calorimetria diferencial de varredura.

Figura 2.17 - A recuperação do alumínio de 99,998\% de pureza, 75\% de deformação por compressão, medido por calorimetria, resistividade elétrica e dureza. Taxa de aquecimento 
Figura 2.18 - Desenho esquemático de um cristal contendo discordâncias em cunha

Figura 2.19 - Representação esquemática do mecanismo de poligonização:

(a) distribuição ao acaso de discordâncias em um monocristal deformado por flexão;

(b) rearranjo das discordâncias ativado termicamente originando os subcontornos (poligonização).

Figura 2.20 - Diagrama esquemático mostrando a velocidade de liberação da energia armazenada nos processo de recuperação e recristalização em função do tempo de recozimento.

Figura 2.21 - Relação entre a fração amolecida e a fração recristalizada para o alumínio (maior EDE) e para o cobre (menor EDE).

Figura 2.22 - Micrografia obtida no MEV de uma amostra de alumínio parcialmente recristalizada.

Figura 2.23 - Diagrama esquemático do processo de recristalização, (a) parcialmente recristalizada, (b) completamente recristalizada.

Figura 2.24 - Fração volumétrica recristalizada do alumínio de alta pureza, 99,998\% de pureza, laminado a $95 \%$ e recozido isotermicamente a $300{ }^{\circ} \mathrm{C}$.

Figura 2.25 - a) Migração de contornos de grão induzida por deformação de um contorno de um grão de baixa energia armazenada $\left(E_{2}\right)$ e um de maior energia $\left(E_{1}\right)$. b) Arrastamento da estrutura de discordâncias atrás da migração do contorno. c) A migração do contorno está livre da estrutura de discordâncias.

Figura 2.26 - A seqüência mostra a nucleação de um grão recristalizado iniciando de um subcontorno: (a) subestrutura inicial; (b) crescimento do subgrão maior sobre os outros menores; e (c) uma área livre de defeitos associado a um contorno de alto ângulo (grão maior) que está sendo formado.

Figura 2.27 - Coalescimento de subgrão pela rotação de um subgrão.

Figura 2.28 - Desenho esquemático do sentido de migração do contorno de ângulo e o sentido de migração de átomos durante o crescimento dos núcleos da recristalização.

Figura 2.29 - Velocidade de migração de contornos de grão em função da diferença de orientação, entre o grão recristalizado e a matriz deformada, no alumínio.

Figura 2.30 - O efeito do Fe em solução sólida na recristalização do alumínio de alta 
pureza.

Figura 2.31 - Ordem de ocorrência da recristalização e precipitação: a) Diagrama de fase esquemático de uma liga com concentração $\mathrm{C}_{0}$ homogeneizada a $\mathrm{T}_{\mathrm{H}}$; b) Curva TTT envolvendo precipitação e recristalização

Figura 2.32 - Desenho esquemático mostrando a precipitação descontínua associada à migração de um contorno de alto ângulo durante a recristalização primária. Ambas a densidade de discordância $\mathrm{N}_{0}$ e a concentração $\mathrm{C}_{0}$ em uma liga deformada e supersaturada são reduzidas a $\mathrm{N}_{1}$ e $\mathrm{C}_{1}$

Figura 2.33 - Diagrama esquemático da zona de deformação e da banda de deformação provocada por uma partícula grosseira $(>1 \mu \mathrm{m})$.

Figura 2.34 - As condições de deformação e tamanho da partícula para que a nucleação ocorra em partículas de alumínio.

Figura 2.35 - Estrutura de grãos mostrando a influência do número de lados na curvatura dos contornos. Os grãos de seis lados estão em equilíbrio.

Figura 2.36 - Representação esquemática da cinética do processo de recristalização secundária.

Figura 2.37 - Chapa com orientação dos cristais ao acaso.

Figura 2.38 - Diagrama esquemático ilustrando as relações entre macrotextura, microtextura e mesotextura.

Figura 2.39 - Categorização das principais técnicas para determinação da textura de acordo com a técnica de difração usada. 99

Figura 2.40 - Goniômetro de textura de geometria de reflexão.

Figura 2.41 - Diagrama esquemático ilustrando o sistema de detecção das figuras de difração de elétrons retroespalhados

Figura 2.42 - Desenho ilustrativo da formação dos cones de difração e as linhas de Kikuchi 103

Figura 2.43 - (a) Família de pólos $\{001\}$ em um cristal cúbico projetado dentro de uma esfera de referência de uma projeção estereográfica. (b) Figura de pólo de um cristal...........

Figura 2.44 - Figura de pólo inversa onde é plotada a direção na amostra, relacionada com direção do cristal, fixada em uma unidade única da projeção estereográfica.

Figura 2.45 - Definição dos ângulos de Euler.

Figura 2.46 - Ábaco de indexação para interpretação das FDO’s. 
Figura 2.47 - Gráfico das fibras de orientação da estrutura CFC no espaço de Euler.

Figura 2.48 - Algumas orientações típicas de deformação e de recristalização no espaço de Euler.

Figura 2.49 - Figuras de pólo típicas do plano $\{111\}$ para o alumínio (a) deformado, (b) deformado e recristalizado (mista) e (c) recristalizado........

Figura 3.1 - Notação de direções adotadas neste trabalho.

Figura 3.2 - Desenho esquemático mostrando a preparação das amostras no estado "como recebido", ao longo da espessura, para as análises da composição química, dureza (HV) e textura cristalográfica.

Figura 3.3 - Desenho esquemático mostrando a preparação das amostras após laminação a frio com $70 \%$ de redução em espessura, ao longo da espessura, para as análises da textura cristalográfica.

Figura 3.4 - Fluxograma das atividades da etapa experimental.

Figura 4.1 - Micrografia mostrando a distribuição dos precipitados na superfície dos alumínios de pureza comercial, no estado "como recebido", polidos mecanicamente e com ataque químico, com aumento de 50X (MO): a) AA1100, b) AA1050 e c) AA1070.

Figura 4.2 - Macrografia mostrando a estrutura na superfície do alumínio super puro, AA1199, no estado "como recebido", polido mecanicamente e com ataque químico, com aumento de 3,2X (microscópio estereoscópio binocular).

Figura 4.3 - Microestrutura na superfície dos alumínios de pureza comercial, no estado "como recebido", polidos e atacados (anodização) eletroliticamente, com aumento de 50X (MO, luz polarizada): a) AA1100, b) AA1050 e c) AA1070.

Figura 4.4 - Microestrutura na superfície do alumínio super puro, no estado "como recebido", polido mecanicamente e atacado (anodização) eletroliticamente, com aumento de 37,5X (MO, luz polarizada).

Figura 4.5 - Microestrutura do alumínio AA1100, no estado "como recebido", polido e atacado (anodização) eletroliticamente, com aumento de 50X (MO, luz polarizada) na seção longitudinal, em diferentes posições: a) periferia, b) semi periferia e c) centro.

Figura 4.6 - Microestrutura do alumínio AA1100, no estado "como recebido", polido e atacado (anodização) eletroliticamente, com aumento de 100X (MO, luz polarizada) na seção longitudinal, em diferentes posições: a) periferia, b) semi periferia e c) centro. 
Figura 4.7 - Microestrutura do alumínio AA1100, no estado "como recebido", polido e atacado (anodização) eletroliticamente, com aumento de 200X (MO, luz polarizada) na seção longitudinal, em diferentes posições: a) periferia, b) semi periferia e c) centro.

Figura 4.8 - Microestrutura do alumínio AA1050, no estado "como recebido", polido e atacado (anodização) eletroliticamente, com aumento de 50X (MO, luz polarizada) na seção longitudinal, em diferentes posições: a) periferia, b) semi periferia e c) centro. 136

Figura 4.9 - Microestrutura do alumínio AA1050, no estado "como recebido", polido e atacado (anodização) eletroliticamente, com aumento de 100X (MO, luz polarizada) na seção longitudinal, em diferentes posições: a) periferia, b) semi periferia e c) centro. 136

Figura 4.10 - Microestrutura do alumínio AA1050, no estado "como recebido", polido e atacado (anodização) eletroliticamente, com aumento de 200X (MO, luz polarizada) na seção longitudinal, em diferentes posições: a) periferia, b) semi periferia e c) centro. 136

Figura 4.11 - Microestrutura do alumínio AA1070, no estado "como recebido", polido e atacado (anodização) eletroliticamente, com aumento de 50X (MO, luz polarizada) na seção longitudinal, em diferentes posições: a) periferia, b) semi periferia e c) centro.

Figura 4.12 - Microestrutura do alumínio AA1070, no estado "como recebido", polido e atacado (anodização) eletroliticamente, com aumento de 100X (MO, luz polarizada) na seção longitudinal, em diferentes posições: a) periferia, b) semi periferia e c) centro.

Figura 4.13 - Microestrutura do alumínio AA1070, no estado "como recebido", polido e atacado (anodização) eletroliticamente, com aumento de 200X (MO, luz polarizada) na seção longitudinal, em diferentes posições: a) periferia, b) semi periferia e c) centro

Figura 4.14 - Microestrutura do alumínio AA1100, no estado "como recebido", polido e atacado (anodização) eletroliticamente, com aumento de 50X (MO, luz polarizada) na seção longitudinal, em diferentes posições: a) periferia, b) semi periferia e c) centro.....

Figura 4.15 - Microestrutura do alumínio AA1100, no estado "como recebido", polido e atacado (anodização) eletroliticamente, com aumento de 100X (MO, luz polarizada) na seção transversal, em diferentes posições: a) periferia, b) semi periferia e c) centro.

Figura 4.16 - Microestrutura do alumínio AA1100, no estado "como recebido", polido e atacado (anodização) eletroliticamente, com aumento de 200X (MO, luz polarizada) na seção transversal, em diferentes posições: a) periferia, b) semi periferia e c) centro.

Figura 4.17 - Microestrutura do alumínio AA1050, no estado "como recebido", polido e atacado (anodização) eletroliticamente, com aumento de 50X (MO, luz polarizada) na 
seção transversal, em diferentes posições: a) periferia, b) semi periferia e c) centro

Figura 4.18 - Microestrutura do alumínio AA1050, no estado "como recebido", polido e atacado (anodização) eletroliticamente, com aumento de 100X (MO, luz polarizada) na seção transversal, em diferentes posições: a) periferia, b) semi periferia e c) centro.

Figura 4.19 - Microestrutura do alumínio AA1050, no estado "como recebido", polido e atacado (anodização) eletroliticamente, com aumento de 200X (MO, luz polarizada) na seção transversal, em diferentes posições: a) periferia, b) semi periferia e c) centro.

Figura 4.20 - Microestrutura do alumínio AA1070, no estado "como recebido", polido e atacado (anodização) eletroliticamente, com aumento de 50X (MO, luz polarizada) na seção transversal, em diferentes posições: a) periferia, b) semi periferia e c) centro

Figura 4.21 - Microestrutura do alumínio AA1070, no estado "como recebido", polido e atacado (anodização) eletroliticamente, com aumento de 100X (MO, luz polarizada) na seção transversal, em diferentes posições: a) periferia, b) semi periferia e c) centro.

Figura 4.22 - Microestrutura do alumínio AA1070, no estado "como recebido", polido e atacado (anodização) eletroliticamente, com aumento de 200X (MO, luz polarizada) na seção transversal, em diferentes posições: a) periferia, b) semi periferia e c) centro.

Figura 4.23 - Micrografia na superfície dos alumínios de pureza comercial, no estado "como recebido", polido mecanicamente sem ataque, com aumento de 500X (MEV, imagem de elétrons retroespalhados): a) AA1100, b) AA1050 e c) AA1070.

Figura 4.24 - Micrografia na superfície do alumínio super puro, no estado "como recebido", polido mecanicamente sem ataque, com aumento de 1000X (MEV, imagem de elétrons secundários).

Figura 4.25 - Espectro de dispersão de energia (EDS) do alumínio AA1100, no estado "como recebido".

Figura 4.26 - Espectro de dispersão de energia (EDS) do alumínio AA1050, no estado "como recebido".

Figura 4.27 - Espectro de dispersão de energia (EDS) do alumínio AA1070, no estado "como recebido"

Figura 4.28 - Espectro de dispersão de energia (EDS) do alumínio AA1199, no estado "como recebido",

Figura 4.29 - Aglomerado de precipitados tipo "roseta modificada" encontrado no alumínio AA1100, no estado "como recebido" polido eletroliticamente e sem ataque 
(MEV, imagens de elétrons retroespalhados).....

Figura 4.30 - Espectro de dispersão de energia (EDS) do aglomerado de precipitados tipo "roseta modificada" do alumínio AA1100, no estado "como recebido"

Figura 4.31 - Precipitado tipo "compacto" encontrado no alumínio AA1100, no estado "como recebido" polido eletroliticamente e sem ataque (MEV, imagens de elétrons retroespalhados).

Figura 4.32 - Espectro de dispersão de energia (EDS) do precipitado tipo "compacto" do alumínio AA1100, no estado "como recebido".

Figura 4.33 - Aglomerado de precipitados tipo "bastonete" encontrado no alumínio AA1100, no estado "como recebido" polido eletroliticamente e sem ataque (MEV, imagens de elétrons retroespalhados).

Figura 4.34 - Espectro de dispersão de energia (EDS) do aglomerado de precipitados tipo "bastonete" do alumínio AA1100, no estado "como recebido"

Figura 4.35 - Aglomerado de precipitados tipo "roseta" encontrado no alumínio AA1100, no estado "como recebido" polido eletroliticamente e sem ataque (MEV, imagens de elétrons retroespalhados)......

Figura 4.36 - Espectro de dispersão de energia (EDS) do aglomerado de precipitados tipo "roseta" do alumínio AA1100, no estado "como recebido".

Figura 4.37 - Precipitado tipo "agulha" encontrado no alumínio AA1050, no estado "como recebido" polido eletroliticamente e sem ataque (MEV, imagens de elétrons retroespalhados).

Figura 4.38 - Espectro de dispersão de energia (EDS) do precipitado tipo "agulha" do alumínio AA1050, no estado "como recebido".

Figura 4.39 - Aglomerado de precipitados tipo "roseta" encontrado no alumínio AA1070, no estado "como recebido" polido eletroliticamente e sem ataque (MEV, imagens de elétrons retroespalhados)

Figura 4.40 - Espectro de dispersão de energia (EDS) do aglomerado de precipitados tipo "roseta" do alumínio AA1070, no estado "como recebido".

Figura 4.41 - Aglomerado de precipitados tipo "bastonete" encontrado no alumínio AA1070, no estado "como recebido" polido eletroliticamente e sem ataque (MEV, imagens de elétrons retroespalhados). 
Figura 4.42 - Espectro de dispersão de energia (EDS) do aglomerado de precipitados tipo "bastonete" do alumínio AA1070, no estado "como recebido"...

Figura 4.43 - Aglomerado de precipitados tipo "roseta-bastonete" encontrado no alumínio AA1070, no estado "como recebido" polido eletroliticamente e sem ataque (MEV, imagens de elétrons retroespalhados).

Figura 4.44 - Espectro de dispersão de energia (EDS) do aglomerado de precipitados tipo "roseta-bastonete" do alumínio AA1070, no estado "como recebido".

Figura 4.45 - Aglomerado de precipitados tipo "irregular" encontrado no alumínio AA1070, no estado "como recebido" polido eletroliticamente e sem ataque (MEV, imagens de elétrons retroespalhados).

Figura 4.46 - Espectro de dispersão de energia (EDS) do aglomerado de precipitados tipo "roseta" do alumínio AA1070, no estado "como recebido".

Figura 4.47 - Condutividade elétrica, dos alumínios no estado "como recebido", em função da pureza do alumínio.

Figura 4.48 - Microdureza, dos alumínios no estado "como recebido", em função da pureza do alumínio.

Figura 4.49 - Curvas da variação da microdureza, dos alumínios no estado "como recebido", em função da distância da superfície.

Figura 4.50 - Curvas da variação da microdureza e da condutividade elétrica, dos alumínios no estado "como recebido", em função da pureza do alumínio.

Figura 4.51 - (a) Figuras de pólo e (b) FDO, análises na superfície do alumínio AA1100 no estado "como recebido" (difração de raios X).

Figura 4.52 - (a) Figuras de pólo e (b) FDO, análises na superfície do alumínio AA1050 no estado "como recebido" (difração de raios X).

Figura 4.53 - (a) Figuras de pólo e (b) FDO, análises na superfície do alumínio AA1070 no estado "como recebido" (difração de raios X).

Figura 4.54 - Textura tipo fibra $\{113\}$ na superfície das amostras de alumínio de pureza comercial, no estado "como recebido".

Figura 4.55 - (a) Figuras de pólo e (b) FDO, análises a 1/4 da superfície do alumínio AA1100 no estado "como recebido" (difração de raios X).

Figura 4.56 - (a) Figuras de pólo e (b) FDO, análises a 1/4 da superfície do alumínio 
AA1050 no estado "como recebido" (difração de raios X).

Figura 4.57 - (a) Figuras de pólo e (b) FDO, análises a 1/4 da superfície do alumínio AA1070 no estado "como recebido" (difração de raios X).

Figura 4.58 - (a) Figuras de pólo e (b) FDO, análises no centro do alumínio AA1100 no estado "como recebido" (difração de raios X).

Figura 4.59 - (a) Figuras de pólo e (b) FDO, análises no centro do alumínio AA1050 no estado "como recebido" (difração de raios X).

Figura 4.60 - (a) Figuras de pólo e (b) FDO, análises no centro do alumínio AA1070 no estado "como recebido" (difração de raios X).

Figura 4.61 - Microestrutura na superfície dos alumínios de pureza comercial, recozidos a $400{ }^{\circ} \mathrm{C}$ por 1 hora, polidos e atacados (anodização) eletroliticamente, com aumento de $50 \mathrm{X}$ (MO, luz polarizada): a) AA1100, b) AA1050 e c) AA1070.

Figura 4.62 - Microestrutura na superfície dos alumínios de pureza comercial, recozidos a $400{ }^{\circ} \mathrm{C}$ por 24 horas, polidos e atacados (anodização) eletroliticamente, com aumento de 50X (MO, luz polarizada): a) AA1100, b) AA1050 e c) AA1070.

Figura 4.63 - Micrografia na superfície dos alumínios de pureza comercial, no estado “como recebido", recozido a $400{ }^{\circ} \mathrm{C} / 1 \mathrm{~h}$, polido mecanicamente sem ataque, com aumento de 500X (MEV, imagem de elétrons retroespalhados): a) AA1100, b) AA1050 e c) AA1070.

Figura 4.64 - Micrografia na superfície dos alumínios de pureza comercial, no estado “como recebido", recozido a $400{ }^{\circ} \mathrm{C} / 24 \mathrm{~h}$, polido mecanicamente sem ataque, com aumento de 500X (MEV, imagem de elétrons retroespalhados): a) AA1100, b) AA1050 e c) AA1070

Figura 4.65 - Condutividade elétrica dos alumínios no estado "como recebido" e após recozimento a $400{ }^{\circ} \mathrm{C}$ por 1 e 24 horas, em função da pureza do alumínio.

Figura 4.66 - Microdureza dos alumínios no estado "como recebido" e após recozimento a $400{ }^{\circ} \mathrm{C}$ por 1 e 24 horas, em função da pureza do alumínio.

Figura 4.67 - Curvas de variação da microdureza e da condutividade elétrica dos alumínios recozidos a $400{ }^{\circ} \mathrm{C}$ por 1 hora, em função da pureza do alumínio.

Figura 4.68 - Curvas da variação da microdureza e da condutividade elétrica dos alumínios recozidos a $400^{\circ} \mathrm{C}$ por 24 horas, em função da pureza do alumínio. 
Figura 4.69 - (a) Figura de pólo 111 e (b) FDO com $\phi_{2}=0^{\circ}$ e $45^{\circ}$, análises na superfície do alumínio AA1100 recozido a $400{ }^{\circ} \mathrm{C} / 1 \mathrm{~h}$ (difração de raios X).

Figura 4.70 - (a) Figura de pólo 111 e (b) FDO com $\phi_{2}=0^{\circ}$ e $45^{\circ}$, análises na superfície do alumínio AA1050 recozido a $400{ }^{\circ} \mathrm{C} / 1$ h (difração de raios X).

Figura 4.71 - (a) Figura de pólo 111 e (b) FDO com $\phi_{2}=0^{\circ}$ e $45^{\circ}$, análises na superfície do alumínio AA1070 recozido a $400{ }^{\circ} \mathrm{C} / 1 \mathrm{~h}$ (difração de raios X)

Figura 4.72 - Textura tipo fibra $\{113\}$, análises na superfície das amostras de alumínio de pureza comercial, recozido a $400{ }^{\circ} \mathrm{C} / 1 \mathrm{~h}$.

Figura 4.73 - (a) Figura de pólo 111 e (b) FDO com $\phi_{2}=0^{\circ}$ e $45^{\circ}$, análises a 1/4 da espessura do alumínio AA1100 recozido a $400{ }^{\circ} \mathrm{C} / 1$ h (difração de raios X)......

Figura 4.74 - (a) Figura de pólo 111 e (b) FDO com $\phi_{2}=0^{\circ}$ e $45^{\circ}$, análises a 1/4 da espessura do alumínio AA1050 recozido a $400{ }^{\circ} \mathrm{C} / 1 \mathrm{~h}$ (difração de raios X).

Figura 4.75 - (a) Figura de pólo 111 e (b) FDO com $\phi_{2}=0^{\circ}$ e $45^{\circ}$, análises a $1 / 4$ da espessura do alumínio AA1070 recozido a $400{ }^{\circ} \mathrm{C} / 1 \mathrm{~h}$ (difração de raios X).

Figura 4.76 - (a) Figura de pólo 111 e (b) FDO com $\phi_{2}=0^{\circ}$ e $45^{\circ}$, análises no centro do alumínio AA1100 recozido a $400{ }^{\circ} \mathrm{C} / 1$ h (difração de raios X).

Figura 4.77 - (a) Figura de pólo 111 e (b) FDO com $\phi_{2}=0^{\circ}$ e 45 , análises no centro do alumínio AA1050 recozido a $400{ }^{\circ} \mathrm{C} / 1 \mathrm{~h}$ (difração de raios X).....

Figura 4.78 - (a) Figura de pólo 111 e (b) FDO com $\phi_{2}=0^{\circ}$ e $45^{\circ}$, análises no centro do alumínio AA1070 recozido a $400{ }^{\circ} \mathrm{C} / 1$ h (difração de raios X).

Figura 4.79 - Figura de pólo 111, análises na superfície do alumínio AA1100 recozido a $400{ }^{\circ} \mathrm{C} / 24 \mathrm{~h}$ (difração de raios $\mathrm{X}$ )......

Figura 4.80 - (a) Figura de pólo 111 e (b) FDO com $\phi_{2}=0^{\circ}$ e $45^{\circ}$, análises na superfície do alumínio AA1050 recozido a $400{ }^{\circ} \mathrm{C} / 24$ h (difração de raios X).

Figura 4.81 - (a) Figura de pólo 111 e (b) FDO com $\phi_{2}=0^{\circ}$ e $45^{\circ}$, análises na superfície do alumínio AA1070 recozido a $400{ }^{\circ} \mathrm{C} / 24$ h (difração de raios X).

Figura 4.82 - Textura tipo fibra $\{113\}$, na superfície das amostras dos alumínios AA1050 e AA1070, recozidos a $400^{\circ} \mathrm{C} / 24 \mathrm{~h}$.

Figura 4.83 - Figura de pólo 111, análises a 1⁄4 da espessura do alumínio AA1100 recozido a $400{ }^{\circ} \mathrm{C} / 24$ h (difração de raios $\mathrm{X}$ ). 
Figura 4.84 - (a) Figura de pólo 111 e (b) FDO com $\phi_{2}=0^{\circ}$ e $45^{\circ}$, análises a 1/4 da espessura do alumínio AA1050 recozido a $400{ }^{\circ} \mathrm{C} / 24$ h (difração de raios X)

Figura 4.85 - (a) Figura de pólo 111 e (b) FDO com $\phi_{2}=0^{\circ}$ e $45^{\circ}$, análises a 1/4 da espessura do alumínio AA1070 recozido a $400{ }^{\circ} \mathrm{C} / 24$ h (difração de raios X).

Figura 4.86 - Textura tipo fibra $\{113\}$, a $1 / 4$ da espessura das amostras dos alumínios AA1050 e AA1070, recozidos a $400{ }^{\circ} \mathrm{C} / 24 \mathrm{~h}$.

Figura 4.87 - Figura de pólo 111, análises no centro do alumínio AA1100 recozido a 400 ${ }^{\circ} \mathrm{C} / 24$ h (difração de raios X)

Figura 4.88 - (a) Figura de pólo 111 e (b) FDO com $\phi_{2}=0^{\circ}$ e $45^{\circ}$, análises no centro do alumínio AA1050 recozido a $400{ }^{\circ} \mathrm{C} / 24$ h (difração de raios X).

Figura 4.89 - (a) Figura de pólo 111 e (b) FDO com $\phi_{2}=0^{\circ}$ e $45^{\circ}$, análises no centro do alumínio AA1070 recozido a $400{ }^{\circ} \mathrm{C} / 24$ h (difração de raios X).

Figura 4.90 - Microestrutura do alumínio super puro laminado a frio com 70\% de redução em espessura, polido mecanicamente e atacado (anodização) eletroliticamente, com aumento de 37,5X (MO, luz polarizada): a) sem tratamento térmico, e tratado termicamente: b) $50{ }^{\circ} \mathrm{C} / 1 \mathrm{~h}$, c) $100{ }^{\circ} \mathrm{C} / 1 \mathrm{~h}$, d) $150{ }^{\circ} \mathrm{C} / 1 \mathrm{~h}$, e) $\left.200{ }^{\circ} \mathrm{C} / 1 \mathrm{~h}, \mathrm{f}\right) 250{ }^{\circ} \mathrm{C} / 1 \mathrm{~h}, \mathrm{~g}$ ) $\left.300{ }^{\circ} \mathrm{C} / 1 \mathrm{~h}, \mathrm{~h}\right) 350{ }^{\circ} \mathrm{C} / 1 \mathrm{~h}$, i) $\left.400{ }^{\circ} \mathrm{C} / 1 \mathrm{~h} \mathrm{e} \mathrm{j}\right) 500{ }^{\circ} \mathrm{C} / 1 \mathrm{~h}$.

Figura 4.91 - Microestruturas dos alumínios laminados a frio com $70 \%$ de redução em espessura e sem tratamento térmico, polidos eletroliticamente: a) AA1100, b) AA1050 e c) AA1070 e polido mecanicamente: d) AA1199, ambos atacados (anodização) eletroliticamente, com aumento de 50X (MO, luz polarizada).

Figura 4.92 - Microestruturas dos alumínios laminados a frio com $70 \%$ de redução em espessura e tratados termicamente a $200{ }^{\circ} \mathrm{C} / 1 \mathrm{~h}$, polidos eletroliticamente: a) AA1100, b) AA1050 e c) AA1070 e polido mecanicamente: d) AA1199, ambos atacados (anodização) eletroliticamente, com aumento de 50X e 37,5X (MO, luz polarizada), respectivamente.

Figura 4.93 - Microestruturas dos alumínios laminados a frio com $70 \%$ de redução em espessura e tratados termicamente a $250{ }^{\circ} \mathrm{C} / 1 \mathrm{~h}$, polidos eletroliticamente: a) AA1100, b) AA1050 e c) AA1070 e polido mecanicamente: d) AA1199, ambos atacados (anodização) eletroliticamente, com aumento de 50X e 37,5X (MO, luz polarizada), respectivamente. Figura 4.94 - Microestruturas dos alumínios laminados a frio com 70\% de redução em espessura e tratados termicamente a $300{ }^{\circ} \mathrm{C} / 1 \mathrm{~h}$, polidos eletroliticamente: a) AA1100, b) 
AA1050 e c) AA1070 e polido mecanicamente: d) AA1199, ambos atacados (anodização) eletroliticamente, com aumento de 50X e 37,5X (MO, luz polarizada), respectivamente.

Figura 4.95 - Microestruturas dos alumínios laminados a frio com $70 \%$ de redução em espessura e tratados termicamente a $350^{\circ} \mathrm{C} / 1 \mathrm{~h}$, polidos eletroliticamente: a) AA1100, b) AA1050 e c) AA1070 e polido mecanicamente: d) AA1199, ambos atacados (anodização) eletroliticamente, com aumento de 50X e 37,5X (MO, luz polarizada), respectivamente.

Figura 4.96 - Microestruturas dos alumínios laminados a frio com $70 \%$ de redução em espessura e tratados termicamente a $400{ }^{\circ} \mathrm{C} / 1 \mathrm{~h}$, polidos eletroliticamente: a) AA1100, b) AA1050 e c) AA1070 e polido mecanicamente: d) AA1199, ambos atacados (anodização) eletroliticamente, com aumento de 50X e 37,5X (MO, luz polarizada), respectivamente........

Figura 4.97 - Desenho esquemático de maclas em materiais com estrutura CFC: (a) parte de um grão maclado; (b) macla completa de faces paralelas; e (c) maclas incompletas de faces paralelas.

Figura 4.98 - Microestrutura do alumínio super puro laminado a frio com $70 \%$ de redução em espessura e tratado termicamente a $400{ }^{\circ} \mathrm{C} / 1 \mathrm{~h}$, polido mecanicamente e atacado (anodização) eletroliticamente, com aumento de 100X (MO, luz polarizada), mostrando uma macla incompleta de faces paralelas

Figura 4.99 - Microestruturas dos alumínios laminados a frio com 70\% de redução em espessura e tratados termicamente a $500{ }^{\circ} \mathrm{C} / 1 \mathrm{~h}$, polidos eletroliticamente: a) AA1100, b) AA1050 e c) AA1070 e polido mecanicamente: d) AA1199, ambos atacados (anodização) eletroliticamente, com aumento de 50X e 37,5X (MO, luz polarizada), respectivamente...

Figura 4.100 - Curvas da variação da microdureza (HV), dos alumínios laminados a frio com $70 \%$ de redução em espessura, em função das temperaturas do tratamento térmico.

Figura 4.101 - Taxa de variação da microdureza (dH/dT), dos alumínios laminados a frio com $70 \%$ de redução em espessura, em função das temperaturas do tratamento térmico....... Figura 4.102 - Curvas da variação da microdureza (HV) dos alumínios laminados a frio com $70 \%$ de redução em espessura, com diferentes temperaturas de tratamento térmico, em função da pureza do alumínio.

Figura 4.103 - Curvas da variação da microdureza (HV) dos alumínios laminados a frio com $70 \%$ de redução em espessura, com diferentes temperaturas de tratamento térmico, em função da pureza do alumínio.

Figura 4.104 - (a) Figura de pólo 111 e (b) FDO com $\phi_{2}=0^{\circ}, 45^{\circ}$ e $65^{\circ}$, na superfície do 
alumínio AA1100, laminado a frio com $70 \%$ de redução em espessura, sem tratamento térmico (difração de raios X).

Figura 4.105 - (a) Figura de pólo 111 e (b) FDO com $\phi_{2}=0^{\circ}, 45^{\circ}$ e $65^{\circ}$, na superfície do alumínio AA1050, laminado a frio com $70 \%$ de redução em espessura, sem tratamento térmico (difração de raios $\mathrm{X}$ )

Figura 4.106 - (a) Figura de pólo 111 e (b) FDO com $\phi_{2}=0^{\circ}, 45^{\circ}$ e $65^{\circ}$, na superfície do alumínio AA1070, laminado a frio com $70 \%$ de redução em espessura, sem tratamento térmico (difração de raios X)

Figura 4.107 - Representação esquemática da textura de laminação de materiais com estrutura CFC no espaço tridimensional de Euler mostrando a fibra $\alpha$ e a fibra $\beta$.

Figura 4.108 - (a) Figuras de pólos e (b) FDO da superfície do alumínio AA1199 laminado a frio com $70 \%$ de redução em espessura, sem tratamento térmico, obtidas por EBSD com simetria triclínica

Figura 4.109 - (a) Figuras de pólos e (b) FDO da superfície do alumínio AA1199 laminado a frio com $70 \%$ de redução em espessura, sem tratamento térmico, obtidas por EBSD com simetria ortorrômbica

Figura 4.110 - (a) Figura de pólo 111 e (b) FDO com $\phi_{2}=0^{\circ}, 45^{\circ}$ e $65^{\circ}$, análises a $1 / 4$ da espessura do alumínio AA1100, laminado a frio com $70 \%$ de redução em espessura, sem tratamento térmico (difração de raios X).

Figura 4.111 - (a) Figura de pólo 111 e (b) FDO com $\phi_{2}=0^{\circ}, 45^{\circ}$ e $65^{\circ}$, análises a 1/4 da espessura do alumínio AA1050, laminado a frio com 70\% de redução em espessura, sem tratamento térmico (difração de raios X)

Figura 4.112 - (a) Figura de pólo 111 e (b) FDO com $\phi_{2}=0^{\circ}, 45^{\circ}$ e $65^{\circ}$, análises a 1/4 da espessura do alumínio AA1070, laminado a frio com $70 \%$ de redução em espessura, sem tratamento térmico (difração de raios X).

Figura 4.113 - (a) Figura de pólo 111 e (b) FDO com $\phi_{2}=0^{\circ}, 45^{\circ}$ e $65^{\circ}$, análises no centro do alumínio AA1100, laminado a frio com $70 \%$ de redução em espessura, sem tratamento térmico (difração de raios $\mathrm{X}$ ).

Figura 4.114 - (a) Figura de pólo 111 e (b) FDO $\operatorname{com} \phi_{2}=0^{\circ}, 45^{\circ}$ e $65^{\circ}$, análises no centro do alumínio AA1050, laminado a frio com $70 \%$ de redução em espessura, sem tratamento térmico (difração de raios $\mathrm{X}$ ) 
Figura 4.115 - (a) Figura de pólo 111 e (b) FDO com $\phi_{2}=0^{\circ}, 45^{\circ}$ e $65^{\circ}$, análises no centro do alumínio AA1070, laminado a frio com $70 \%$ de redução em espessura, sem tratamento térmico (difração de raios $\mathrm{X}$ )

Figura 4.116 - (a) Figura de pólo 111 e (b) FDO na superfície do alumínio AA1199, laminado a frio com $70 \%$ de redução em espessura, tratado termicamente a $150{ }^{\circ} \mathrm{C} / 1 \mathrm{~h}$ (EBSD) com simetria triclínica.

Figura 4.117 - Mapa de orientação de grãos e a figura de pólo inversa do alumínio AA1199, laminado a frio com $70 \%$ de redução em espessura, tratado termicamente a 150 ${ }^{\circ} \mathrm{C} / 1 \mathrm{~h}$

Figura 4.118 - (a) Figura de pólo 111 e (b) FDO na superfície do alumínio AA1199, laminado a frio com $70 \%$ de redução em espessura, tratado termicamente a $200{ }^{\circ} \mathrm{C} / 1 \mathrm{~h}$ (EBSD) com simetria triclínica

Figura 4.119 - (a) Figura de pólo 111 e (b) FDO com $\phi_{2}=0^{\circ}, 45^{\circ}$ e $65^{\circ}$, na superfície do alumínio AA1100, laminado a frio com $70 \%$ de redução em espessura, tratado termicamente a $250^{\circ} \mathrm{C} / 1 \mathrm{~h}$ (difração de raios $\left.\mathrm{X}\right)$.

Figura 4.120 - (a) Figura de pólo 111 e (b) FDO com $\phi_{2}=0^{\circ}, 45^{\circ}$ e $65^{\circ}$, na superfície do alumínio AA1050, laminado a frio com $70 \%$ de redução em espessura, tratado termicamente a $250^{\circ} \mathrm{C} / 1 \mathrm{~h}$ (difração de raios $\left.\mathrm{X}\right)$.

Figura 4.121 - (a) Figura de pólo 111 e (b) FDO com $\phi_{2}=0^{\circ}, 45^{\circ}$ e $65^{\circ}$, na superfície do alumínio AA1070, laminado a frio com $70 \%$ de redução em espessura, tratado termicamente a $250^{\circ} \mathrm{C} / 1 \mathrm{~h}$ (difração de raios $\left.\mathrm{X}\right)$.....

Figura 4.122 - (a) Figura de pólo 111 e (b) FDO na superfície do alumínio AA1199, laminado a frio com $70 \%$ de redução em espessura, tratado termicamente a $250{ }^{\circ} \mathrm{C} / 1 \mathrm{~h}$ (EBSD) com simetria triclínica.

Figura 4.123 - (a) Figura de pólo 111 e (b) FDO com $\phi_{2}=0^{\circ}, 45^{\circ}$ e $65^{\circ}$, na superfície do alumínio AA1100, laminado a frio com $70 \%$ de redução em espessura, tratado termicamente a $300{ }^{\circ} \mathrm{C} / 1 \mathrm{~h}$ (difração de raios $\mathrm{X}$ ).

Figura 4.124 - (a) Figura de pólo 111 e (b) FDO com $\phi_{2}=0^{\circ}, 45^{\circ}$ e $65^{\circ}$, na superfície do alumínio AA1050, laminado a frio com $70 \%$ de redução em espessura, tratado termicamente a $300{ }^{\circ} \mathrm{C} / 1 \mathrm{~h}$ (difração de raios $\left.\mathrm{X}\right)$

Figura 4.125 - (a) Figura de pólo 111 e (b) FDO com $\phi_{2}=0^{\circ}, 45^{\circ}$ e $65^{\circ}$, na superfície do 
alumínio AA1070, laminado a frio com $70 \%$ de redução em espessura, tratado termicamente a $300{ }^{\circ} \mathrm{C} / 1 \mathrm{~h}$ (difração de raios $\mathrm{X}$ ).

Figura 4.126 - (a) Figura de pólo 111 e (b) FDO na superfície do alumínio AA1199, laminado a frio com $70 \%$ de redução em espessura, tratado termicamente a $300{ }^{\circ} \mathrm{C} / 1 \mathrm{~h}$ com simetria triclínica (EBSD).

Figura 4.127 - Mapa de orientação de grãos e a figura de pólo inversa do alumínio AA1199, laminado a frio com $70 \%$ de redução em espessura, tratado termicamente a 300 ${ }^{\circ} \mathrm{C} / 1 \mathrm{~h}$.

Figura 4.128 - (a) Figura de pólo 111 e (b) FDO com $\phi_{2}=0^{\circ}, 45^{\circ}$ e $65^{\circ}$, na superfície do alumínio AA1100, laminado a frio com $70 \%$ de redução em espessura, tratado termicamente a $350^{\circ} \mathrm{C} / 1 \mathrm{~h}$ (difração de raios $\mathrm{X}$ ).

Figura 4.129 - (a) Figura de pólo 111 e (b) FDO com $\phi_{2}=0^{\circ}, 45^{\circ}$ e 65 , na superfície do alumínio AA1050, laminado a frio com $70 \%$ de redução em espessura, tratado termicamente a $350^{\circ} \mathrm{C} / 1 \mathrm{~h}$ (difração de raios $\mathrm{X}$ ).

Figura 4.130 - (a) Figura de pólo 111 e (b) FDO com $\phi_{2}=0^{\circ}, 45^{\circ}$ e $65^{\circ}$, na superfície do alumínio AA1070, laminado a frio com $70 \%$ de redução em espessura, tratado termicamente a $350^{\circ} \mathrm{C} / 1 \mathrm{~h}$ (difração de raios $\mathrm{X}$ ).

Figura 4.131 - (a) Figura de pólo 111 e (b) FDO, ambos triclínicos e na superfície do alumínio AA1199, laminado a frio com $70 \%$ de redução em espessura, tratado termicamente a $350^{\circ} \mathrm{C} / 1 \mathrm{~h}(\mathrm{EBSD})$

Figura 4.132 - (a) Figura de pólo 111 e (b) FDO com $\phi_{2}=0^{\circ}, 45^{\circ}$ e $65^{\circ}$, a $1 / 4$ da espessura do alumínio AA1100, laminado a frio com $70 \%$ de redução em espessura, tratado termicamente a $350^{\circ} \mathrm{C} / 1 \mathrm{~h}$ (difração de raios $\mathrm{X}$ ).

Figura 4.133 - (a) Figura de pólo 111 e (b) FDO com $\phi_{2}=0^{\circ}, 45^{\circ}$ e $65^{\circ}$, a $1 / 4$ da espessura do alumínio AA1050, laminado a frio com $70 \%$ de redução em espessura, tratado termicamente a $350^{\circ} \mathrm{C} / 1 \mathrm{~h}$ (difração de raios $\mathrm{X}$ ).

Figura 4.134 - (a) Figura de pólo 111 e (b) FDO com $\phi_{2}=0^{\circ}, 45^{\circ}$ e $65^{\circ}$, a $1 / 4$ da espessura do alumínio AA1070, laminado a frio com $70 \%$ de redução em espessura, tratado termicamente a $350^{\circ} \mathrm{C} / 1 \mathrm{~h}$ (difração de raios $\mathrm{X}$ ).

Figura 4.135 - (a) Figura de pólo 111 e (b) FDO com $\phi_{2}=0^{\circ}, 45^{\circ}$ e $65^{\circ}$, no centro do alumínio AA1100, laminado a frio com $70 \%$ de redução em espessura, tratado 
termicamente a $350^{\circ} \mathrm{C} / 1 \mathrm{~h}$ (difração de raios $\mathrm{X}$ ).

Figura 4.136 - (a) Figura de pólo 111 e (b) FDO com $\phi_{2}=0^{\circ}, 45^{\circ}$ e $65^{\circ}$, no centro do alumínio AA1050, laminado a frio com $70 \%$ de redução em espessura, tratado termicamente a $350^{\circ} \mathrm{C} / 1 \mathrm{~h}$ (difração de raios $\left.\mathrm{X}\right)$.

Figura 4.137 - (a) Figura de pólo 111 e (b) FDO com $\phi_{2}=0^{\circ}, 45^{\circ}$ e $65^{\circ}$, no centro do alumínio AA1070, laminado a frio com $70 \%$ de redução em espessura, tratado termicamente a $350^{\circ} \mathrm{C} / 1 \mathrm{~h}$ (difração de raios $\mathrm{X}$ ).

Figura 4.138 - (a) Figura de pólo 111 e (b) FDO com $\phi_{2}=0^{\circ}, 45^{\circ}$ e $65^{\circ}$, na superfície do alumínio AA1100, laminado a frio com $70 \%$ de redução em espessura, tratado termicamente a $500^{\circ} \mathrm{C} / 1 \mathrm{~h}$ (difração de raios $\left.\mathrm{X}\right)$.

Figura 4.139 - (a) Figura de pólo 111 e (b) FDO com $\phi_{2}=0^{\circ}, 45^{\circ}$ e $65^{\circ}$, na superfície do alumínio AA1050, laminado a frio com $70 \%$ de redução em espessura, tratado termicamente a $500{ }^{\circ} \mathrm{C} / 1 \mathrm{~h}$ (difração de raios $\left.\mathrm{X}\right)$.

Figura 4.140 - (a) Figura de pólo 111 e (b) FDO com $\phi_{2}=0^{\circ}, 45^{\circ}$ e $65^{\circ}$, na superfície do alumínio AA1070, laminado a frio com $70 \%$ de redução em espessura, tratado termicamente a $500{ }^{\circ} \mathrm{C} / 1 \mathrm{~h}$ (difração de raios $\mathrm{X}$ ).

Figura 4.141 - (a) Figura de pólo 111 e (b) FDO, ambos triclínicos e na superfície do alumínio AA1199, laminado a frio com $70 \%$ de redução em espessura, tratado termicamente a $500^{\circ} \mathrm{C} / 1 \mathrm{~h}(\mathrm{EBSD})$

Figura 4.142 - Evolução da textura na superfície do alumínio AA1100, laminado a frio com $70 \%$ de redução em espessura e tratado termicamente, análises obtidas por difração de raios $X$

Figura 4.143 - Evolução da textura na superfície do alumínio AA1050, laminado a frio com $70 \%$ de redução em espessura e tratado termicamente, análises obtidas por difração de raios $\mathrm{X}$

Figura 4.144 - Evolução da textura na superfície do alumínio AA1070, laminado a frio com $70 \%$ de redução em espessura e tratado termicamente, análises obtidas por difração de raios $\mathrm{X}$

Figura 4.145 - Evolução da textura na superfície do alumínio AA1199, laminado a frio com $70 \%$ de redução em espessura e tratado termicamente, análises obtidas por EBSD.

Figura 4.146 - Microestruturas dos alumínios laminados a frio com $80 \%$ de redução em espessura e sem tratamento térmico, polidos e atacados (anodização) eletroliticamente, com 
aumento de 50X (MO, luz polarizada): a) AA1100, b) AA1050 e c) AA1070.

Figura 4.147 - Microestruturas dos alumínios laminados a frio com 80\% de redução em espessura e tratados termicamente a $250{ }^{\circ} \mathrm{C} / 1 \mathrm{~h}$, polidos e atacados (anodização) eletroliticamente, com aumento de 50X (MO, luz polarizada): a) AA1100, b) AA1050 e c) AA 1070.

Figura 4.148 - Microestruturas dos alumínios laminados a frio com 80\% de redução em espessura e tratados termicamente a $250{ }^{\circ} \mathrm{C} / 2 \mathrm{~h}$, polidos e atacados (anodização) eletroliticamente, com aumento de 50X (MO, luz polarizada): a) AA1100, b) AA1050 e c) AA1070

Figura 4.149 - Microestruturas dos alumínios laminados a frio com 80\% de redução em espessura e tratados termicamente a $250{ }^{\circ} \mathrm{C} / 3 \mathrm{~h}$, polidos e atacados (anodização) eletroliticamente, com aumento de 50X (MO, luz polarizada): a) AA1100, b) AA1050 e c) AA1070

Figura 4.150 - Microestruturas dos alumínios laminados a frio com 80\% de redução em espessura e tratados termicamente a $250{ }^{\circ} \mathrm{C} / 4 \mathrm{~h}$, polidos e atacados (anodização) eletroliticamente, com aumento de 50X (MO, luz polarizada): a) AA1100, b) AA1050 e c) AA1070

Figura 4.151 - Microestruturas dos alumínios laminados a frio com 80\% de redução em espessura e tratados termicamente a $350{ }^{\circ} \mathrm{C} / 30 \mathrm{~min}$, polidos e atacados (anodização) eletroliticamente, com aumento de 50X (MO, luz polarizada): a) AA1100, b) AA1050 e c) AA1070

Figura 4.152 - Microestruturas dos alumínios laminados a frio com 80\% de redução em espessura e tratados termicamente a $350{ }^{\circ} \mathrm{C} / 1 \mathrm{~h}$, polidos e atacados (anodização) eletroliticamente, com aumento de 50X (MO, luz polarizada): a) AA1100, b) AA1050 e c) AA1070

Figura 4.153 - Curvas da variação da microdureza, dos alumínios de pureza comercial, em função das temperaturas e dos tempos de tratamento térmico.

Figura 4.154 - Curvas da variação da microdureza (HV), dos alumínios de pureza comercial laminados a frio com $80 \%$ de redução em espessura, em função das temperaturas do tratamento térmico.

Figura 4.155 - Taxa de variação da microdureza (dH/dT), dos alumínios de pureza comercial laminados a frio com $80 \%$ de redução em espessura, em função das temperaturas 
do tratamento térmico

Figura 4.156 - Microestruturas dos alumínios de pureza comercial laminados a frio com $80 \%$ de redução em espessura sem tratamento térmico (a, c, e) e tratados isotermicamente a $250{ }^{\circ} \mathrm{C} / 1 \mathrm{~h}(\mathrm{~b}, \mathrm{~d}, \mathrm{f})$, obtidas por microscopia eletrônica de transmissão (MET)

Figura 4.157 - Microestrutura do alumínio AA1070 laminado a frio com 80\% de redução em espessura sem tratamento térmico 


\section{LISTA DE TABELAS}

Tabela 2.1 - Principais propriedades do alumínio no estado recozido.......................... 46

Tabela 2.2 - Algumas aplicações dos alumínios comercialmente puro.

Tabela 2.3 - Limites de composições químicas, em \% em peso, dos alumínios com quatro diferentes níveis de pureza.

Tabela 2.4 - Solubilidade (\% em peso) dos principais elementos de liga do alumínio, nos sistemas binários.

Tabela 2.5 - Índices de Miller e ângulos de Euler das orientações mais importantes do $\mathrm{Al}$ e ligas de $\mathrm{Al}$ após a laminação e recristalização (aproximadamente).....

Tabela 4.1 - Composições químicas nominais (\% em peso), ao longo da espessura, dos alumínios de pureza comercial e na superfície do alumínio super puro, no estado "como recebido". As amostras foram analisadas utilizando-se um espectrômetro de emissão óptica.

Tabela 4.2 - Fração volumétrica dos precipitados dos alumínios de pureza comercial no estado "como recebido"

Tabela 4.3 - Diâmetro médio dos grãos dos alumínios no estado "como recebido".

Tabela 4.4 - Condutividade elétrica dos alumínios no estado "como recebido".

Tabela 4.5 - Microdureza Vickers $(0,05 \mathrm{~kg})$ dos alumínios no estado "como recebido", na superfície

Tabela 4.6 - Composições químicas nominais (\% em peso), ao longo da espessura, dos alumínios de pureza comercial, recozidos a $400{ }^{\circ} \mathrm{C} / 1 \mathrm{~h}$ e $24 \mathrm{~h}$. As amostras foram analisadas utilizando-se um espectrômetro de emissão óptica.

Tabela 4.7 - Fração volumétrica dos precipitados dos alumínios de pureza comercial recozidos a $400{ }^{\circ} \mathrm{C}$ por 1 e 24 horas

Tabela 4.8 - Diâmetro médio dos grãos dos alumínios recozidos a $400{ }^{\circ} \mathrm{C}$ por 1 e 24 horas

Tabela 4.9 - Valores de condutividade elétrica dos alumínios de pureza comercial, após serem recozidos a $400{ }^{\circ} \mathrm{C}$ por 1 e 24 horas.

Tabela 4.10 - Valores de microdureza Vickers $(0,05 \mathrm{~kg})$ dos alumínios de pureza comercial, após serem recozidos a $400{ }^{\circ} \mathrm{C}$ por 1 e 24 horas.

Tabela 4.11 - Direções e intensidades das componentes de textura, análises feitas na 
superfície das amostras dos alumínios de pureza comercial no estado "como recebido" e recozidos a $400^{\circ} \mathrm{C}$ por 1 e 24 horas.....

Tabela 4.12 - Direções e intensidades das componentes de textura, análises feitas a 1/4 da espessura, das amostras dos alumínios de pureza comercial no estado "como recebido" e recozidos a $400^{\circ} \mathrm{C}$ por 1 e 24 horas.

Tabela 4.13 - Direções e intensidades das componentes de textura, análises feitas no centro, das amostras dos alumínios de pureza comercial no estado "como recebido" e recozidos a $400^{\circ} \mathrm{C}$ por 1 e 24 horas.

Tabela 4.14 - Temperatura para 50\% de amolecimento e para completa recristalização dos alumínios de pureza comercial e do alumínio super puro. 


\section{LISTA DE SIGLAS E SÍMBOLOS}
A Fração amolecida
Al Alumínio
c/a Relação entre as arestas da estrutura cristalina hexagonal compacta
$\mathrm{C}_{0} \quad$ Concentração inicial do soluto
$\mathrm{C}_{1} \quad$ Concentração do soluto na região recozida
CFC Cúbica de Face Centrada
$\mathrm{Cr} \quad$ Cromo
$\mathrm{Cu} \quad$ Cobre
DC Direct Chill
DDWs Dense Dislocation Walls
DL Direção de Laminação
DN Direção Normal
DT Direção Transversal
$\mathrm{E}_{1} \quad$ Energia armazenada no grão 1
$\mathrm{E}_{2} \quad$ Energia armazenada no grão 2
EBSD Electron Back-Scatter Diffraction
EDE Energia de Defeito de Empilhamento
$\mathrm{F}_{\mathrm{C}} \quad$ Força motriz devido à precipitação descontínua
FDO Função de Distribuição de Orientação
$\mathrm{Fe} \quad$ Ferro
$\mathrm{F}_{\mathrm{N}} \quad$ Força motriz de eliminação de discordâncias ou contornos de grãos
Ga Gálio
GNBs Geometrically Necessary Boundaries
HB Hardness Brinnel
$\mathrm{H}_{\mathrm{e}} \quad$ Dureza do material encruado
$\mathrm{H}_{\mathrm{r}} \quad$ Dureza do material recristalizado
$\mathrm{H}_{\mathrm{x}} \quad$ Dureza da amostra em questão
IACS International Annealed Copper Standard
IDB Incidental Dislocation Boundaries
L Condição de crescimento
LBs Lamellar Boundaries
m Mobilidade do contorno
MBs MicroBands 
MET Microscópio Eletrônico de Transmissão

MEV Microscópio Eletrônico de Varredura

$\mathrm{Mg} \quad$ Magnésio

Mn Manganês

$\mathrm{N}_{0} \quad$ Densidade de discordâncias na região encruada

$\mathrm{N}_{1} \quad$ Densidade de discordâncias na região recozida

$\mathrm{Ni} \quad$ Níquel

PSN Particle Stimulated Nucleation

r $\quad$ Raio médio das partículas

SAC Selected Area Channeling

SAD Selected Area (electron) Diffraction

SEM Scanning Electron Microscope

Si Silício

SIBM Strain Induced grain Boundary Migration

T Temperatura

$\mathrm{T}_{1} \quad$ Temperatura no instante 1

$\mathrm{T}_{2} \quad$ Temperatura no instante 2

TEM Transmission Electron Microscope

$\mathrm{T}_{\mathrm{f}} \quad$ Temperatura de fusão absoluta

$\mathrm{T}_{\mathrm{H}} \quad$ Temperatura de homogeneização

Ti Titânio

tP Início de precipitação

$\mathrm{T}_{\mathrm{R}} \quad$ Temperatura de têmpera

$t_{R} \quad$ Início de recristalização

TTT Temperatura, Tempo e Transformação

V Vanádio

V Velocidade de migração dos contornos de grão

$\mathrm{V}_{\mathrm{V}} \quad$ Fração volumétrica

Zn Zinco

$\gamma \quad$ Energia superficial do contorno de grão

$\Delta \mathrm{E} \quad$ Diferença de energia armazenada

$\Delta \mathrm{P} \quad$ Somatória de potenciais termodinâmicos e forças retardadoras que atuam sobre o contorno 


\section{SUMÁRIO}

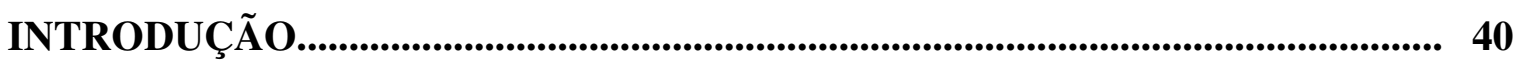

2 REVISÃO BIBLIOGRÁFICA................................................................... 42

2.1 Produção do alumínio..................................................................................................... 42

2.1.1 A indústria do alumínio........................................................................................ 42

2.1.2 Vantagens do alumínio............................................................................................. 43

2.2 Propriedades e aplicações do alumínio da série 1XXX............................................ 45

2.3 Diagramas de fases do alumínio................................................................................. 48

2.3.1 Sistema Al-Fe............................................................................................................... 48

2.3.2 Sistema Al-Fe-Si............................................................................................... 49

2.3.3 Solutos no alumínio.................................................................................................... 49

2.4 Fabricação (Processamento)........................................................................................ 51

2.4.1 Processo de solidificação....................................................................................... 51

2.4.2 Tratamento térmico de homogeneização.............................................................. 55

2.4.3 Laminação............................................................................................................. 57

2.4.3.1 Laminação a quente................................................................................................ 59

2.4.3.2 Laminação a frio........................................................................................... 62

2.50 estado deformado (encruamento)........................................................................ 64

2.5.1 Evolução microestrutural durante a deformação................................................. 66

2.5.2 Heterogeneidades de deformação..................................................................... 67

2.5.2.1 Bandas de deformação............................................................................................ 68

2.5.2.2 Bandas de dobramento............................................................................................ 69

2.5.2.3 Bandas de transiçãa................................................................................................... 69

2.5.2.4 Bandas de cisalhamento............................................................................ 70

2.5.2.5 Microbandas............................................................................................ 70

2.5.3 Fatores que afetam a estrutura dos metais deformados...................................... 71

2.5.3.1 A energia do defeito de empilhamento (EDE).................................................. 71

2.5.3.2 Átomos de soluto............................................................................................ 72

2.5.3.3 Partículas de segunda fase............................................................................... 72

2.5.3.4 A temperatura de deformação............................................................................ 73

2.5.3.5 A velocidade de deformação................................................................................ 73

2.5.3.6 0 tamanho de grão inicial........................................................................................ 73 
2.6 Recuperação, recristalização e crescimento de grão............................................ 74

2.6.1 Recuperação............................................................................................................... 74

2.6.2 Competição entre recuperação e recristalização............................................... 79

2.6.3 Recristalização........................................................................................ 82

2.6.3.1 Nucleação da recristalização.................................................................................... 84

2.6.3.2 Crescimento de grão na recristalização............................................................. 88

2.6.4 Encruamento, recuperação e recristalização de metais impuros e ligas.......... 89

2.6.4.1 Soluções sólidas................................................................................................... 90

2.6.4.2 Precipitação durante a recristalização.......................................................... 90

2.6.4.3 Dispersão de partículas.................................................................................. 92

2.6.5 Crescimento de grão............................................................................................................... 94

2.6.5.1 Crescimento normal de grão.................................................................................... 95

2.6.5.2 Recristalização secundária (crescimento anormal de grão)........................... 96

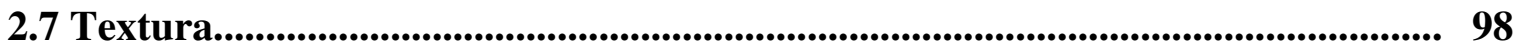

2.7.1 Análise da macrotextura .............................................................................. 100

2.7.2 Análise da microtextura...................................................................................... 101

2.7.3 Representação da textura................................................................................ 103

2.7.4 Textura em ligas de alumínio........................................................................... 108

2.7.5 Textura de laminação a quente do alumínio............................................................ 111

2.7.6 Textura de laminação a frio em materiais CFC............................................... 111

2.7.7 Textura de recristalização em materiais CFC............................................................ 112

2.7.7.1 Efeito da nucleação em estruturas do tipo bandas na textura......................... 114

2.7.7.2 Efeito da nucleação nas vizinhanças dos contornos de grão na textura......... 114

2.7.7.3 Efeito da nucleação em bandas de cisalhamento na textura......................... 115

2.7.7.4 Efeito da nucleação estimulada por partículas de segunda fase na textura. 115

3 MATERIAIS E MÉTODOS.............................................................................. 117

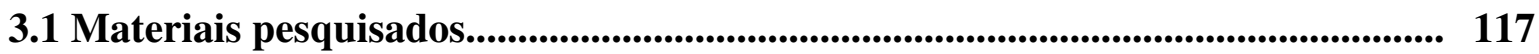

3.1.1 Composição química...................................................................................................... 119

3.1.2 Processamento dos alumínios.......................................................................... 119

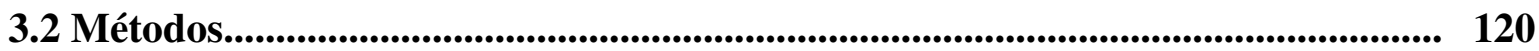

3.2.1 Métodos experimentais........................................................................................ 120

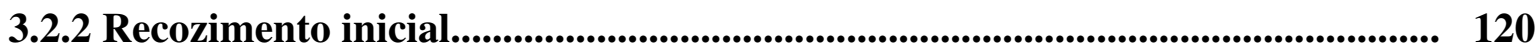

3.2.3 Laminação a frio........................................................................................................................ 121 
3.2.4 Tratamento térmico das amostras laminadas.

3.3 Técnicas de análise microestrutural........................................................................... 122

3.3.1 Preparação metalográfica.............................................................................. 123

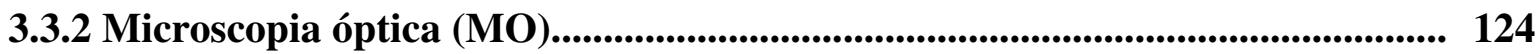

3.3.3 Microscopia óptica com luz polarizada....................................................................... 125

3.3.4 Microscopia eletrônica de varredura (MEV)........................................................ 126

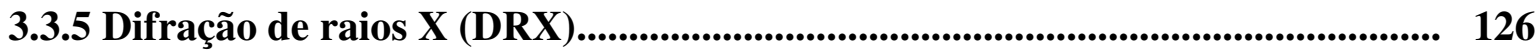

3.3.6 Condutividade elétrica........................................................................................ 127

3.3.7 Microdureza Vickers (HV)....................................................................... 127

3.3.8 Microscopia eletrônica de transmissão (MET))............................................ 128

4 RESULTADOS E DISCUSSÕES............................................................................. 129

4.1 Alumínios no estado como "recebido".................................................................... 130

4.1.1 Composição química................................................................................................... 130

4.1.2 Microscopia óptica (MO)............................................................................... 131

4.1.3 Microscopia eletrônica de varredura (MEV)................................................... 143

4.1.4 Fração volumétrica dos precipitados............................................................ 151

4.1.5 Diâmetro médio dos grãos................................................................................... 152

4.1.6 Condutividade elétrica................................................................................ 153

4.1.7 Microdureza (HV) ..................................................................................................... 154

4.1.8 Microdureza e condutividade elétrica.......................................................... 156

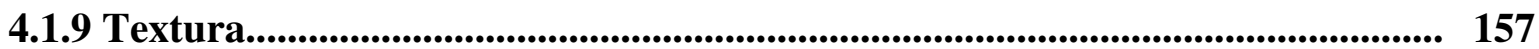

4.1.9.1 Análises feitas na superfície das amostras de alumínio de pureza comercial no estado "como recebido".

4.1.9.2 Análises feitas a $1 / 4$ da espessura das amostras de alumínio de pureza comercial no estado "como recebido",

4.1.9.3 Análises feitas no centro ( $1 / 2$ da espessura) das amostras de alumínio de pureza comercial no estado “como recebido".............................................................. 165

4.2 Amostras após recozimento a $400{ }^{\circ} \mathrm{C}$................................................................................. 169

4.2.1 Composição química........................................................................................... 169

4.2.2 Microscopia óptica (MO)................................................................................. 170

4.2.3 Microscopia eletrônica de varredura (MEV).................................................. 173

4.2.4 Fração volumétrica dos precipitados.......................................................... 174

4.2.5 Diâmetro médio dos grãos........................................................................................................ 175 
4.2.6 Condutividade elétrica.

4.2.7 Microdureza (HV)............................................................................................. 177

4.2.8 Microdureza e condutividade elétrica................................................................... 178

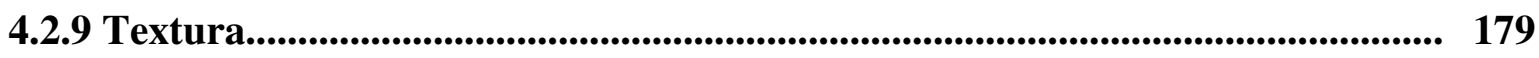

4.2.9.1 Análises feitas na superfície das amostras de alumínio de pureza

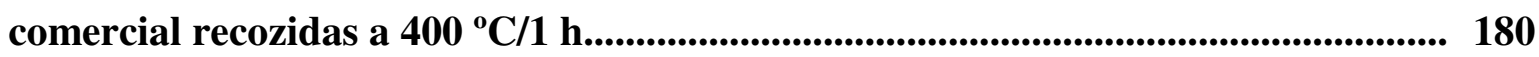

4.2.9.2 Análises feitas a $1 / 4$ da espessura das amostras de alumínio de pureza comercial recozidas a $400{ }^{\circ} \mathrm{C} / 1 \mathrm{~h}$.

4.2.9.3 Análises feitas no centro ( $1 / 2$ da espessura) das amostras de alumínio de pureza comercial recozidas a $400{ }^{\circ} \mathrm{C} / 1 \mathrm{~h}$

4.2.9.4 Análises feitas na superfície das amostras de alumínio de pureza comercial recozidas a $400{ }^{\circ} \mathrm{C} / 24 \mathrm{~h}$.

4.2.9.5 Análises feitas a $1 / 4$ da espessura das amostras de alumínio de pureza comercial recozidas a $400{ }^{\circ} \mathrm{C} / 24 \mathrm{~h}$.

4.2.9.6 Análises feitas no centro ( $1 / 2$ da espessura) das amostras de alumínio de pureza comercial recozidas a $400{ }^{\circ} \mathrm{C} / 24 \mathrm{~h}$.

4.3 Laminação a frio com aproximadamente $70 \%$ de redução em espessura (alumínios de pureza comercial e alumínio super puro).

4.3.1 Alumínio laminado a frio com $70 \%$ de redução em espessura, sem tratamento térmico.

4.3.2 Alumínio laminado a frio com $70 \%$ de redução em espessura, tratado termicamente a $200{ }^{\circ} \mathrm{C} / 1 \mathrm{~h}$.

4.3.3 Alumínio laminado a frio com $70 \%$ de redução em espessura, tratado termicamente a $250{ }^{\circ} \mathrm{C} / 1 \mathrm{~h}$.

4.3.4 Alumínio laminado a frio com $70 \%$ de redução em espessura, tratado termicamente a $300{ }^{\circ} \mathrm{C} / 1 \mathrm{~h}$.

4.3.5 Alumínio laminado a frio com $70 \%$ de redução em espessura, tratado termicamente a $350{ }^{\circ} \mathrm{C} / 1 \mathrm{~h}$.

4.3.6 Alumínio laminado a frio com $70 \%$ de redução em espessura, tratado termicamente a $400{ }^{\circ} \mathrm{C} / 1 \mathrm{~h}$.

4.3.7 Alumínio laminado a frio com $70 \%$ de redução em espessura tratado termicamente a $500{ }^{\circ} \mathrm{C} / 1 \mathrm{~h}$. 
4.3.9.1 Análises feitas na superfície das amostras de alumínio, laminadas com $70 \%$ de redução em espessura, sem tratamento térmico.

4.3.9.2 Análises feitas a $1 / 4$ da espessura das amostras de alumínio, laminadas com $70 \%$ de redução em espessura, sem tratamento térmico.

4.3.9.3 Análises feitas no centro ( $1 / 2$ da espessura) das amostras de alumínio, laminadas com $70 \%$ de redução em espessura, sem tratamento térmico.

4.3.9.4 Análises feitas na superfície das amostras de alumínio, laminadas com $70 \%$ de redução em espessura e tratadas termicamente a $150{ }^{\circ} \mathrm{C} / 1 \mathrm{~h}$

4.3.9.5 Análises feitas na superfície das amostras de alumínio, laminadas com $70 \%$ de redução em espessura e tratadas termicamente a $200{ }^{\circ} \mathrm{C} / 1 \mathrm{~h}$.

4.3.9.6 Análises feitas na superfície das amostras de alumínio, laminadas com $70 \%$ de redução em espessura e tratadas termicamente a $250{ }^{\circ} \mathrm{C} / 1 \mathrm{~h}$.

4.3.9.7 Análises feitas na superfície das amostras de alumínio, laminadas com $70 \%$ de redução em espessura e tratadas termicamente a $300{ }^{\circ} \mathrm{C} / 1 \mathrm{~h}$.

4.3.9.8 Análises feitas na superfície das amostras de alumínio, laminadas com $70 \%$ de redução em espessura e tratadas termicamente a $350{ }^{\circ} \mathrm{C} / 1 \mathrm{~h}$.

4.3.9.9 Análises feitas a $1 / 4$ da espessura das amostras de alumínio, laminadas com $70 \%$ de redução em espessura e tratadas termicamente a $350{ }^{\circ} \mathrm{C} / 1 \mathrm{~h}$

4.3.9.10 Análises feitas no centro ( $1 / 2$ da espessura) das amostras de alumínio, laminadas com $70 \%$ de redução em espessura e tratadas termicamente a 350 ${ }^{\circ} \mathrm{C} / 1$ h.

4.3.9.11 Análises feitas na superfície das amostras de alumínio, laminadas com $70 \%$ de redução em espessura e tratadas termicamente a $500{ }^{\circ} \mathrm{C} / 1 \mathrm{~h}$.

4.4 Laminação a frio com aproximadamente $80 \%$ de redução em espessura (alumínios de pureza comercial )

4.4.1 Alumínio laminado a frio com $80 \%$ de redução em espessura, sem tratamento térmico.

4.4.2 Alumínio laminado a frio com $80 \%$ de redução em espessura e tratado termicamente a $250{ }^{\circ} \mathrm{C} / 1 \mathrm{~h}$.

4.4.3 Alumínio laminado a frio com $80 \%$ de redução em espessura e tratado termicamente a $250{ }^{\circ} \mathrm{C} / 2 \mathrm{~h}$. 
4.4.4 Alumínio laminado a frio com $80 \%$ de redução em espessura e tratado termicamente a $250{ }^{\circ} \mathrm{C} / 3 \mathrm{~h}$.

4.4.5 Alumínio laminado a frio com $80 \%$ de redução em espessura e tratado termicamente a $250{ }^{\circ} \mathrm{C} / 4 \mathrm{~h}$

4.4.6 Alumínio laminado a frio com $80 \%$ de redução em espessura e tratado termicamente a $350{ }^{\circ} \mathrm{C} / 30 \mathrm{~min}$.

4.4.7 Alumínio laminado a frio com $80 \%$ de redução em espessura e tratado

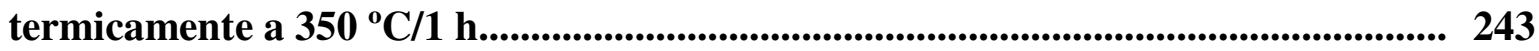

4.4.8 Microdureza (HV) ....................................................................................................... 244

4.4.9 Microscopia eletrônica de transmissão (MET)........................................... 246

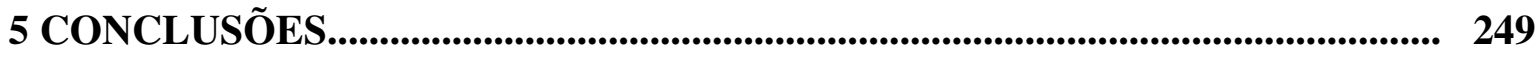

6 REFERÊNCIAS BIBLIOGRÁFICAS........................................................................ 252 